Aim of the study: Cellular resistance is strongly correlated with the risk of failure in doxorubicin (DOX) treatment, and the knowledge of the mechanisms of resistance and its possible modulation is still very limited. Material and methods: In this study, we assessed the effect of $5 \%$ Selol and DOX on the expression of genes that affect cell proliferation in the resistant KB-V1 and sensitive HeLa cell lines, using RT2 ProfilerTM PCR Array matrix "Human Cancer Drug Resistance and Metabolism" (SABiosciences).

Results: We showed that HeLa and KBV1 cell lines, characterised by varying susceptibility to DOX, have different genetic profiles as regards the studied genes. KB-V1 cells show overexpression of $M Y C$ and $B C L 2$ genes, which encode proteins with anti apoptotic properties. Selol, when used in KB-V1 cells, reduced the expression of MYC and $B C L 2$ genes, suggested as a new therapeutic target in the treatment of cancers resistant to cytostatic drugs. Conclusions: The results suggest that Selol could be used as a modulator that enhances the cytotoxic effects of doxorubicin, particularly in cells resis tant to this drug.

Key words: Selol, doxorubicin, drug resistance, qRT-PCR, expression, genes.

Contemp Oncol (Pozn) 2014; 18 (2): 90-94 DOI: $10.5114 /$ WO.2014.40558

\section{Comparison of selected gene expression profiles in sensitive and resistant cancer cells treated with doxorubicin and Selol}

\author{
Jadwiga Dudkiewicz-Wilczyńska ${ }^{1}$, Agnieszka Grabowska ${ }^{1}$, Iza Książek \\ Karolina Sitarz ${ }^{1}$, Piotr Suchocki ${ }^{1,2}$, Elżbieta Anuszewska ${ }^{1}$
}

${ }^{1}$ National Medicines Institute, Warsaw, Poland

${ }^{2}$ Medical University of Warsaw, Poland

\section{Introduction}

Doxorubicin (DOX) is one of the commonly used drugs in the treatment of many cancers, including cervical cancer. Unfortunately, its effectiveness is often limited due to the growing phenomenon of secondary resistance. Numerous studies evaluating new therapeutic compounds or improvement in the activity of the existing compounds, such as liposomal doxycycline or pegylated doxycycline, testify about the search for new therapeutic solutions. Compounds that would increase sensitivity to known cytostatic drugs in cancer are also sought for. For several years, in cooperation with the Medical University of Warsaw (WUM), we carry out studies on 5\% Selol, an organic compound containing selenium +IV, in the form of a mixture of selenotriglycerides [1]. Intensive research to determine its anticancer mechanism of action is ongoing [2-5]. Earlier studies revealed that Selol enhances the cytotoxic effect of doxorubicin in human cervical cancer cells (HeLa), and shows a cytotoxic effect in cells resistant to doxorubicin (KB-V1) [6]. An analysis of the effect of Selol on the expression of genes responsible for multi-drug resistance, performed as part of the same study, has not shown any inhibition of overexpression of MDR family genes, which encode membrane transporters, in either type of cells. However, some effects were shown in KB-V1 cells, including reduced BCL2 gene expression and increased GSTP1 gene expression [6]. Some authors suggest that the anti-apoptotic effect of the protein encoded by the $B C L 2$ gene can be achieved, inter alia, by inhibiting the production of free radicals; the resulting reduction in its expression will have pro-apoptotic effect. This hypothesis may be confirmed by increased expression of the GSTP1 gene, encoding the enzymatic protein involved in defence against oxidative stress, observed in KB-V1 cells. These results suggest a putative pro-oxidative mechanism of action of Selol, consisting in induction of free radical formation, particularly noticeable in the resistant cells, characterised by a reduced defence against oxidative stress.

As already mentioned, cellular resistance is strongly correlated with the risk of failure in DOX treatment; however, the knowledge of the mechanisms of resistance and its possible modulation is still very limited. Research aimed at understanding these mechanisms is still needed.

In this study, we evaluated the effect of 5\% Selol and DOX on the expression of another group of genes, found in the $\mathrm{RT}^{2}$ Profiler ${ }^{\mathrm{TM}} \mathrm{PCR}$ Array matrix "Human Cancer Drug Resistance and Metabolism" (SABiosciences), belonging to the functional groups responsible for the cell cycle, encoding growth factors and transcription factors as well as hormone receptors and DNA repair genes in resistant and sensitive cell lines (KB-V1 and HeLa, respectively). The analysis of gene expression profile depending on cell type and 
compound used will contribute to a better understanding of the Selol mechanism of action.

\section{Material and methods}

The material for the study consisted of human cervical cancer HeLa cells and its subline KB-V1 (German Collection), cultured in EMEM (Lonza) medium $\left(5 \% \mathrm{CO}_{2}, 37^{\circ} \mathrm{C}\right)$, supplemented with 10\% FBS (Gibco). After 24 hours of incubation, DOX at a concentration of $0.29 \mu \mathrm{g} / \mathrm{ml}$ or DOX with added $5 \%$ Selol in quantity corresponding to $10 \mathrm{\mu g} /$ $\mathrm{ml}$ selenium were added to the culture, and incubation was continued for another 24 hours. The concentrations of DOX and Selol were selected on the basis of previous studies [6]. The control sample was a cell culture performed in the medium alone (without xenobiotics). Isolation and purification of the isolated RNA and cDNA synthesis were performed according to the procedure provided by the manufacturer of RNeasy Mini Kit (Qiagen). Quantitative analysis of gene expression was performed on the $\mathrm{RT}^{2}$ Profiler ${ }^{T M}$ PCR Array matrix "Human Cancer Drug Resistance and Metabolism" using a dedicated set of reagents SABiosciences RT ${ }^{2}$ qPCR Master Mix, in a MX3005p system (Stratagene). Analysis of the results by the $\Delta \Delta C_{T}$ method was performed according to the instructions of the matrix manufacturer.

The conditions of the experiments, materials and methods were the same as previously described [6].

\section{Results}

We compared gene expression in KB-V1 cells to the expression determined in HeLa cells, under controlled conditions (Table 1), and after 24 hours of incubation with DOX, and gene expression was determined and compared to the expression obtained in the corresponding control culture (Table 2). The main objective of this study was to evaluate the effect of 24-hour combined administration of DOX and 5\% Selol on the expression profile of the examined genes. A comparative analysis of gene expression obtained in HeLa and KB-V1 cells, treated with these compounds, was performed in relation to gene expression in the corresponding control culture (Table 3). Only genes for which at least a threefold difference in expression was shown are presented in the Tables.

\section{Comments on the findings and discussion}

It seemed that evaluation of the expression profile of genes which have important functions in cell proliferation would be an important issue to improve the knowledge of the mechanism of action of Selol in both cell types. Proliferation is the result of a series of processes that occur in the correct order and are interdependent, known as the cell cycle, which is initiated and controlled by a number of proteins and their complexes. In this study, we evaluated the expression of 8 genes encoding proteins of the cell cycle: cyclin D1 and E1, CDK2, CDK34, CDKN1A, CDKN1B, CDKN2A and CDKN2D. Cell division is also affected by growth factors or nuclear hormones secreted by adjacent cells. From this group, the following genes encoding growth factor receptors were studied: ERBB1, EERBB2, ERBB3, ERBB4, FGF2, IGF1R, IGF2R, MET, and genes encoding hormone receptors: AR, ESR1, ESR2, PPARA, PPARD, PPARG, RARA, RARB, RARG, RXRA and RXRB. The expression of genes encoding the following transcription factors was also studied: AHR, AP1S1, ELK1, FOS, HIF1A, MYC, NFKB1, NFKB2, NFKBIB, NFKBIE, RELB, TNFRSF11A.

To demonstrate the differences in the genetic characteristics of the cells used in the study, a comparative analysis of expression of the examined genes was performed in cells exhibiting resistance to DOX and in sensitive cells,

Table 1. Expression profile of selected genes in the control culture of KB-V1 cells as compared to HeLa cells. Changes in expression $(\geq 3)$ are marked as follows: “个” - increase, “ $\downarrow$ ” - reduction

\begin{tabular}{lcc|} 
Functional gene & \multicolumn{2}{c}{ KBV-1 control / HeLa control } \\
groupings & Gene symbol & qRT-PCR fold change \\
& ATM & $3.78 \uparrow$ \\
DNA repair & MSH2 & $3.76 \uparrow$ \\
Cell cycle & - & - \\
\hline Growth factor receptors & ERBB3 & $39.10 \uparrow$ \\
& ERBB4 & $25.97 \uparrow$ \\
Hormone receptors & AR & $89.02 \downarrow$ \\
& ESR1 & $3.91 \uparrow$ \\
Transcription factors & MYC & $4.18 \uparrow$ \\
& TNFRSF11A & $3.68 \uparrow$
\end{tabular}

Table 2. The effect of DOX on changes $(\geq 3)$ in the expression profile of selected genes in sensitive and resistant cell lines, as compared to the cells in the corresponding control culture.

$\begin{array}{lcccc}\text { Functional gene groupings } & \begin{array}{c}\text { HeLa }+ \text { DOX } / \text { HeLa control } \\ \text { Gene symbol }\end{array} & \text { qRT-PCR fold change } & \begin{array}{c}\text { KB-V1+ Dox / KB-V1 control } \\ \text { Gene symbol }\end{array} & \text { qRT-PCR fold change } \\ \text { DNA repair } & - & - & - & - \\ \text { Cell cycle } & \text { CDKN1A } & 3.29 \uparrow & \text { CDKN1A } & 4.05 \uparrow \\ \text { Growth factor receptors } & \text { ERBB3 } & 5.36 \uparrow & \text { ERBB4 } & \text { IGF1R } \\ \text { Hormone receptors } & \text { ERBB4 } & 4.52 \uparrow & A .56 \downarrow & 3.09 \downarrow \\ \text { Transcription factors } & \text { ESR1 } & 8.06 \uparrow & \text { MYC } & 4.18 \uparrow\end{array}$

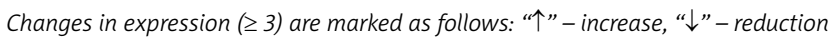


Table 3. The effect of DOX and $5 \%$ Selol on changes $(\geq 3)$ in the expression profile of selected genes in sensitive and resistant cell lines, as compared to the cells in the corresponding control culture. Changes in expression $(\geq 3)$ are marked as follows: “ $\uparrow$ ” - increase, “ $\downarrow$ ” - reduction

\begin{tabular}{|c|c|c|c|c|}
\hline \multirow{2}{*}{ Functional gene groupings } & \multicolumn{2}{|c|}{ HeLa + DOX + Sel / HeLa control } & \multicolumn{2}{|c|}{ KB-V1 + DOX + Sel / KB-V1 control } \\
\hline & Gene symbol & qRT-PCR fold change & Gene symbol & qRT-PCR fold change \\
\hline DNA repair & $X P C$ & $4.20 \uparrow$ & ATM & $4.40 \downarrow$ \\
\hline Cell cycle & CDKN1A & $3.97 \uparrow$ & $\begin{array}{c}\text { CDKN1A } \\
\text { CDKN2D } \\
\text { CCNE1 }\end{array}$ & $\begin{array}{l}3.16 \uparrow \\
4.82 \uparrow \\
3.69 \uparrow\end{array}$ \\
\hline Growth factor receptors & $\begin{array}{l}E R B B 3 \\
E R B B 4\end{array}$ & $\begin{array}{c}29.30 \uparrow \\
9.87 \uparrow\end{array}$ & $\begin{array}{l}I G F 1 R \\
E G F R\end{array}$ & $\begin{array}{l}4.03 \downarrow \\
3.11 \downarrow\end{array}$ \\
\hline Hormone receptors & $\begin{array}{c}A R \\
P P A R D \\
R A R G\end{array}$ & $\begin{array}{l}5.83 \uparrow \\
3.01 \uparrow \\
5.06 \uparrow\end{array}$ & $\begin{array}{c}A R \\
P P A R A \\
R A R G\end{array}$ & $\begin{array}{l}22.8 \uparrow \\
6.31 \downarrow \\
7.43 \downarrow\end{array}$ \\
\hline Transcription factors & $\begin{array}{c}\text { NFKB2 } \\
\text { RELB } \\
\text { MYC }\end{array}$ & $\begin{array}{l}5.73 \uparrow \\
5.50 \uparrow \\
3.38 \downarrow\end{array}$ & $\begin{array}{l}\text { AHR } \\
\text { RELB } \\
\text { MYC }\end{array}$ & $\begin{array}{c}3,47 \uparrow \\
6.40 \uparrow \\
12.03 \downarrow\end{array}$ \\
\hline
\end{tabular}

cultured under control conditions (without any xenobiotic). Analysis of the results showed a more than 3-fold higher expression of two genes (ATM, MSH2) from the DNA repair group, more than 20-fold higher expression of two genes (ERBB3, ERBB4) belonging to the group of growth factor receptors, and approximately fourfold higher expression of the MYC and TNFRSF11A genes from the group of transcription factors in KB-V1 cells as compared to HeLa cells. A significantly reduced expression (> 80x) was shown for the $A R$ gene encoding the androgen receptor protein, whereas the ESR1 gene encoding the oestrogen receptor protein showed increased expression. No differences were observed in the expression of cell cycle genes in either cell type (Table 1).

Literature data indicate that overexpression of ATM and $\mathrm{MSH} 2$ genes in a cell leads to an increased expression of proteins involved in the detection of DNA damage and repair, which leads to inhibition of apoptosis. Similarly, $E R B B 3$ and ERBB4 genes belonging to the ERBB family, and their expression products are involved in the processes of growth, proliferation, apoptosis, protein secretion, differentiation, and cell movement. They also play an important role in many cancer processes, where these genes often undergo amplification and abnormal expression, possibly leading to oncogenic activation. Moreover, a very potent proto-oncogene in cancer cells is the MYC gene, which encodes a protein that increases cell proliferation by affecting, inter alia, the regulation of angiogenesis [7-9]. In our study we found that the expression of this gene was 4-fold higher in KB-V1 cells exhibiting resistance to DOX compared to sensitive HeLa cells.

Based on a comparative analysis of gene expression in cells treated with DOX, in relation to gene expression determined in the respective control cell culture (without DOX), we found a varied effect of the cytostatic agent on the expression of the examined genes, depending on the cell type (Table 2). Doxorubicin caused no changes $(\geq 3 \times)$ in the expression of the examined genes involved in the cellular DNA repair function. However, DOX caused a similar response in both cell types in transcription activation of the CDKN1A gene, encoding the p21 protein, which is an inhibitor of cyclin-dependent kinases, acting as a regulator of the cell cycle. In the cells treated with DOX, a differentiated response was seen for genes encoding growth factor receptors or transcription factors; namely, in HeLa cells, there was an increase of ERBB3, ERBB4, and RELB gene expression, and in KB-V1 cells, there was reduced expression of ERBB4, IGF1R and MYC. Increased expression occurred for genes belonging to hormone receptors, ESR1 and $A R$, in both HeLa and KB-V1 cells. However, a direct comparison of the expression of these genes in the control cells showed that their expression, excluding the $A R$ gene, is many times stronger in the resistant cells (Table 1). Based on the above comparison it can be concluded that the response to DOX was dependent on the initial expression of these genes in a given cell. It can be assumed that the changes observed in the expression of these genes are presumably additional factors behind the differences in the cytotoxic activity of DOX on the tested cells, established in the first part of the study [6]. The reasons for this phenomenon can also be seen in the increased expression of another gene belonging to transcription factors, i.e. the RELB gene, which was only seen in the HeLa cell culture following DOX induction (Table 2). The RelB protein, encoded by this gene, is included in class II proteins of the nuclear factor kappa (NF- $\kappa B)$. In contrast to class I proteins (NF- $\kappa B 1, N F-\kappa B 2)$ encoded by the NFKB1 and NFKB2 genes, the RelB proteins form homodimers, which lack the capacity to bind factor NF-KB, and thus its activation. Inactive NF- $\mathrm{NB}$ proteins do not enter the nucleus and cannot act as transcription factors (bind to DNA). This leads to inhibition of transcription in a cell and causes abnormal proliferation.

The combined administration of DOX and Selol caused varied changes in the expression of many genes, depending on the type of cell (Table 3). In HeLa cells, increased expression of eight genes was seen: XPC, ERBB3, ERBB4, 
$A R, P P A R D, R A R G, N F K B 2$ and $R E L B$, and reduced expression of only one gene, MYC. The response seen in KB-V1 cells had the opposite direction, as the expression of the six genes was reduced: ATM, IGF1R, EGF1R, PPARA, RARG and MYC. There was an increase in the expression of three genes involved in the cell cycle: CDKN1A, CDKN2D and CCNE1, and also the $A R, A H R$ and RELB genes. It was also found that following combined administration of the tested compounds, there was an opposite direction of changes in the expression of PPARD and RARG genes in the cells, for which no differences were found in the baseline level. In HeLa cells, their expression was increased relative to the control, whereas in KB-V1 cells their expression was clearly reduced (Table 3 ). Protein products encoded by the genes of the PPAR family act as transcription factors that regulate the expression of target genes; they are also involved in the development of immune response, especially in the course of inflammatory response. Their activation increases lipid catabolism [10]. However, the significant increase in expression of the ERBB3, ERBB4 genes, seen in this study but only in the HeLa cells, could be associated with an increase in expression of the NFKB2 gene encoding the main activator of nuclear factor NF- B.

An increase in expression of the $A H R$ gene, which is usually inactive in the cell, was only seed in KB-V1 cells cultured with DOX and Selol. Under the effect of some xenobiotics, this gene can be activated, which leads to induction of enzymes participating in the metabolism and the formation of toxic metabolites. In the KB-V1 cells, in duction of the metabolic pathway by the $A H R$ gene is likely due to the lower, compared to HeLa cells, expression of the CYP1A1, CYP1A2, CYP2D6, GSTP1 genes, which encode enzymes responsible for the metabolism of drugs [6].

The inhibitory effect of DOX on the MYC gene expression is well known [11]. In this study, this effect of DOX on the $c-M Y C$ gene was also confirmed, but in addition, the results suggesting an increase in this effect following Selol treatment seem highly promising. In the culture of the tested cells treated with Selol, stronger inhibition of the MYC gene transcription was found in KB-V1 cells. Probably Selol, by strong inhibition (suppression) of a very important oncogene, responsible, among other things, for angiogenesis, may potentiate the cytotoxic effect of DOX, causing a reduction in the proliferation of not only sensitive HeLa cells, but also the cell subline KB-V1 showing resistance to DOX.

We showed in our study that the two cell lines, HeLa and KB-V1, characterised by varying susceptibility to the effect of DOX, have different genetic profiles. In the first part of the study, we showed a significant overexpression of the genes of the $A B C$ family, the $B C L 2$ gene and 3 genes responsible for drug metabolism (CYP1A2, CYP2C19, GSTP10) in the cells exhibiting resistance to DOX, compared to the expression of these genes determined in HeLa cells [6]. In this part of the study, we also showed overexpression of the following genes: ATM, MSH2, ERBB3, ERBB4, AR, ESR1, MYC and TNFRSF11A. Based on the above summary, we can conclude that the differences in the genetic profile of KB-V1 cells showing resistance to DOX, compared with sensitive HeLa cells, are seen not only in genes that encode membrane transport proteins and drug-metabolising enzymes but also those encoding proteins involved in the pathways associated with transcription factors and growth factors, playing an important role in the activation of angiogenesis and metastasis, thus providing an increased proliferation of these cells. There is a number of literature reports on the studies of the complex interactions between different factors and cellular pathways that are activated by cytotoxic drugs. These mechanisms are very important for understanding the complex cell genome response, as well as for determining the potential therapeutic targets, as well as understanding the molecular mechanisms of action of chemotherapeutic agents. Of particular importance is research aimed at the discovery of compounds with cytotoxic activity in cells exhibiting multi-drug resistance $[12,13]$. Recently, much work is focused on a clear understanding of the function of the MYC gene because it is overexpressed in as many as about 70\% of cancers, which leads to a state of hyperproliferation and cancer progression. The search for compounds having a regulating effect on the amplification of this gene has been identified as a new therapeutic target [14-19].

Kim et al. [20] demonstrated in their study that increased expression of c-myc protein in multi-drug resistant cells (MDR) plays a critical role in overcoming multidrug resistance by TRAIL (tumour necrosis factor-related apoptosis-inducing ligand). The tumour necrosis factor ligand that induces apoptosis is a type II membrane protein that belongs to the TNF (tumour necrosis factor) family, which acts as a specific sensitizer, adding to the cytotoxic effect of various compounds including doxorubicin [20]. Poor therapeutic outcomes are also associated with the treatment of refractory metastatic cancer with concomitant overexpression of $\mathrm{c}-\mathrm{Myc}$ and $\mathrm{BCl}-2$. The significance of using these two genes as a therapeutic target in order to improve the efficacy of treatment strategies was explained in the work of Sasaki et al. [21]. By using specific inhibitors that block overexpression of these genes, these authors showed increased susceptibility to apoptosis of B-cell lymphoma with induced inhibition of the $\mathrm{Bcl}-2$ gene compared to c-Myc. However, simultaneous inhibition of the expression of both these genes was preferred [22]. KB-V1 cells used in our study showed increased expression of the MYC gene, as well as the $B C L 2$ gene. The suppression of the expression of both genes was found in the cell culture with Selol; at the same time, induction of apoptosis was seen [6]. It is likely that sensitisation of cells to the cytotoxic effects of doxorubicin by Selol is a result of its blocking action on the expression of both these genes. Therefore, Selol is an interesting potential anticancer compound, as it enables more effective treatment of chemo-resistant tumours. The action of Selol shown in our study is aimed at the currently tested new therapeutic target, related to damping the expression of the MYC and BCL2 genes. We need further research to demonstrate the activity of Selol as an inhibitor of these genes. Earlier studies of Suchocki et al. [5] showed a stronger pro-apoptotic activity of Sel$\mathrm{ol}$, when used at a concentration of $20 \mu \mathrm{g} \mathrm{Se}$, in $\mathrm{HL} / 60$ DOX resistant cells, by sensitising these cells to the cytostatic drug used. In this study, no increased activity of the 
caspase family of enzymes was seen, and there was no significant effect on the cell cycle parameters evaluated. However, changes in the mitochondrial membrane potential and lysozyme distribution were reported [5]. Olm et al. also reported a beneficial effect of a selenium compound in the treatment of multi-drug-resistant AML cells in their study [22], showing that selenium increases the expression of TRXR1 and GRX proteins, which could suggest its effect on oxidative stress. Our results, indicating the significant changes in the expression of many genes after Selol treatment, leading to disruption of cellular processes and functions, significantly explain the mechanism of the cytotoxic action of this compound in both types of cells tested.

Undoubtedly, the mechanism of action of the new selenium compound is complex and requires further research. Further studies will aim to explain the effect of Selol on the response of genes involved in cellular stress.

In conclusions:

1. The HeLa and KB-V1 cell lines, used in this study, characterised by varying susceptibility to the effect of DOX, have different genetic profiles as regards the examined genes.

2. The differences in the genetic profile of KB-V1 cells as compared to HeLa cells not only refer to genes of the MDR and CYP families, but also genes that encode proteins involved in the pathways associated with transcription factors and growth factors, as well as those responsible for DNA repair.

3. KB-V1 cells show overexpression of $M Y C$ and $B C L 2$ genes, which encode proteins with anti-apoptotic properties.

4. Selol, when used in KB-V1 cells, reduces the expression of MYC and BCL2 genes, suggested as a new therapeutic target in the treatment of cancers resistant to cytostatic drugs.

5. Selol is a potential modulator that enhances the cytotoxic effects of doxorubicin, particularly in cells resistant to this drug.

The authors declare no conflict of interest.

This investigation partly was supported by Foundation for Polish Science (Fundacja na rzecz Nauki Polskiej, FNP).

\section{References}

1. Fitak B, Grabowski M, Suchocki P. Pol. PI 176530 (Cl. A61K31/095).

2. Dudkiewicz-Wilczyńska J, Książek I, Nowak K, Suchocki P, Flis S, Kiljan M, Anuszewska E. Study of the effect of Selol and sodium selenite on HeLa cells in vitro. Chemik 2011; 65: 105-14.

3. Falqueiro AM, Primo FL, Morais PC, Mosiniewicz-Szablewska E, Suchocki P, Tedesco AC. Selol-loaded magnetic nanocapsules: A new approach for hyperthermia cancer therapy. J Appl Physics 2011; 109: 306-9.

4. Suchocki P, Misiewicz-Krzemińska I, Skupińska K, Niedźwiecka K, Lubelska K, Fijałek Z, Kasprzycka-Guttman T. Selenitetriglicerydes affect CYP1A1 and QR activity by involvement of reactive oxygen species and Nrf2 transcription factor. Pharmacol Rep 2010; 62: 352-61.
5. Suchocki P, Misiewicz I, Skupinska K, Waclawek K, Fijalek Z, Kasprzycka-Guttman T. The activity of Selol in multidrug-resistant and sensitive human leukemia cells. Oncol Rep 2007; 18: 893-9.

6. Dudkiewicz-Wilczyska J, Grabowska A, Książek I, Nowak K, Anuszewska E. Badanie wpływu Selolu na ekspresję genów kodujących transportery błonowe i enzymy metabolizujące leki w komórkach nowotworowych wrażliwych i opornych. AAMS (Annales Academiae Medicae Silesiensis) 2011; 65: 7-13.

7. Baudino TA, McKay C, Pendeville-Samain H, et al. c-Myc is essential for vasculogenesis and angiogenesis during development and tumor progression. Genes Dev 2002; 16: 2530-43.

8. Bernard S, Eilers M. Control of cell proliferation and growth by Myc proteins. Results Probl Cell Differ 2006; 42: 329-42.

9. Rodrigues CO, Nerlick ST, White EL, Cleveland JL, King ML. A MycSlug (Snail2)/Twist regulatory circuit directs vascular development. Development 2008; 135: 1903-11.

10. Sokołowska M, Kowalski ML, Pawliczak R. Receptory aktywowane przez proliferatory peroksysomów-g (PPAR-g) oraz ich rola w immunoregulacji i kontroli reakcji zapalnej. Postępy Hig Med Dosw 2005; 59: 472-84

11. Pourquier P, Montaudon D, Huet S, Larrue A, Clary A, Robert J. Doxorubicin-induced alterations of c-myc and c-jun gene expression in rat glioblastoma cells: Role of c-jun in drug resistance and cell death. Biochem Pharmacol 1998; 55: 1963-71.

12. Kohno K, Uchiumi T, Niina I, et al. Transcription factors and drug resistance. Eur J Cancer 2005; 41: 2577-2586.

13. Huang Y, Sadée W. Drug sensitivity and resistance genes in cancer chemotherapy: a chemogenomics appoach. Drug Discov Today 2003; 8: 356-63.

14. Robert J, Vekris A, Pourquier P, Bonnet J. Predicting drug response based on gene expression. Crit Rev Oncol Hematol 2004; 51: 205-27.

15. Vita M, Henriksson M. The Myc oncoprotein as a therapeutic target for human cancer. Semin Cancer Biol 2006; 16: 318-330.

16. Larsson LG, Henriksson MA. The Yin and Yang functions of the Myc oncoprotein in cancer development and as targets for therapy. Exp Cell Res 2010; 316: 1429-37.

17. Frenzel A, Zirath H, Vita M, Albihn A, Henriksson MA. Identification of cytotoxic drugs that selectively target tumor cells with MYC overexpression. PLoS One 2011; 6: e27988.

18. Yeh PY, Lu YS, Ou DL, Cheng AL. Ikappa B kinases increase Myc protein stability and enhance progression of breast cancer cells. Mol Cancer 2011; 10: 53-65.

19. den Hollander J, Rimpi S, Doherty JR, et al. Aurora kinases A and B are up-regulated by Myc and are essential for maintenance of the malignant state. Blood 2010; 116: 1498-505.

20. Kim DY, Kim MJ, Kim HB, Lee JW, Bae JH, Kim DW, Kang CD, Kim $\mathrm{SH}$. Suppression of multidrug resistance by treatment with TRAIL in human ovarian and breast cancer cells with high level of c-Myc. Biochim Biophys Acta 2011; 1812: 796-805.

21. Sasaki N, Kuroda J, Nagoshi $\mathrm{H}$, et al. Bcl-2 is a better therapeutic target than c-Myc, but attacking both could be a more effective treatment strategy for B-cell lymphoma with concurrent $\mathrm{Bcl}-2$ and c-Myc overexpression. Exp. Hematol 2011; 39: 817-28.

22. Olm E, Jönsson-Videsäter K, Ribera-Cortada I, et al. Selenite is a potent cytotoxic agent for human primary AML cells. Cancer Lett 2009; 282: 116-23.

\section{Address for correspondence}

Jadwiga Dudkiewicz-Wilczyńska MD, PhD

National Medicines Institute

Chełmska 30/34

00-725 Warsaw, Poland

e-mail: jdwilczynska@gmail.com

Submitted: 13.11 .2012

Accepted: 13.01 .2014 